\title{
DESIGN AND ANALYSIS OF HYDRAULIC PALLET SYSTEM IN CHAIN CONVEYOR
}

\author{
Setu Dabhi ${ }^{1}$, Amey Jadhav ${ }^{2}$, Mukesh Agrawal ${ }^{3}$, Raunak Gadkari ${ }^{4}$, Himanshu Gambhire ${ }^{5}$ \\ ${ }^{1}$ Mechanical Engineering Department, Sinhgad Institute of Technology and Science Narhe, University Of Pune, Pune \\ ${ }^{2}$ Mechanical Engineering Department, Sinhgad Institute of Technology and Science Narhe, University Of Pune, Pune \\ ${ }^{3}$ Mechanical Engineering Department, Sinhgad Institute of Technology and Science Narhe, University Of Pune, Pune \\ ${ }^{4}$ Mechanical Engineering Department, Sinhgad Institute of Technology and Science Narhe, University Of Pune, Pune \\ ${ }^{5}$ Mechanical Engineering Department, Sinhgad Institute of Technology and Science Narhe, University Of Pune, Pune
}

\begin{abstract}
This paper describes the design and analysis of hydraulic pallet system in a chain conveyor used in automobile industries for loading and unloading of materials.The system, consisting of a hydraulic power pack, a chain conveyor, a pallet system is automatically controlled with the help of PLC. Our aim is to design a feasible and a cost effective mechanism to lift the given load using hydraulic actuation and listing merits of hydraulic actuations over pneumatic and servo actuation. The design module pallet along with mechanism used for balancing is design in CAD software CATIA and analyzed for variable loading in ANSYS.The design proposed is highly flexible with the manufactures requirement and its stability is analyzed under variable load. The result of the feasibility study showed a conspicuous shortening of working hours, and an alleviation of manual labor.
\end{abstract}

Keywords-CATIA, ANSYS, Synthesis of Mechanism, Force Analysis $* * *$

\section{INTRODUCTION}

The manufacturer required a pallet system which is to be hydraulic actuated, rather than pneumatically or servo actuated. Comparing the three systems, we find pneumatic system rather advantageous over the other two. Merits of pneumatic system are listed below:

- Simplicity in design

- Cost effective

- Safety and reliability

In spite of the above advantages, it was found that hydraulic system could handle more load as compared to the previous , and the back pressure so developed in hydraulic actuation could efficiently be handled as compared to pneumatic during movement of the pallet, so as maintaining stability and reducing the amount of vibrations. Considering the involvement of the third system, where actuation of the pallet is via servo motors is out of question ,as its highly costly, requires frequent maintenance, and its load bearing capacity is also low as compared to others.

The main advantage of using hydraulic system in our application over pneumatic other than the load bearing capacity is the fluid in hydraulic system is basically incompressible, hence it leads to minimum springing action. So even if the load on the pallet is non uniform, the actuators will balance the pallet in such a way so as to minimize the chances of over throwing the load. This sort of safety measure is difficult to achieve using pneumatic actuation, and even in case of uniform loading the vibration encountered is much more.

\section{COMPONENTS OF THE SYSTEM}

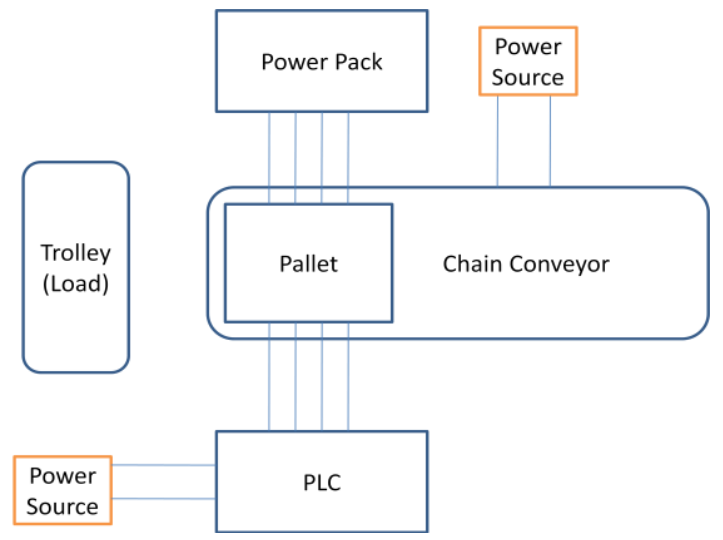

Fig.1: Components of the System

The conveyor system is divided into two sub categories, the Hardware and the Software. The Hardware consists of following parts:

- Chain Conveyor

- Pallet system

- Hydraulic Power Pack

- Hoses and Pipes

- Sensors 
The software part consists of PLC programming using the standard PLC and its software provided by the manufacturer. The main focus of our research consists of designing the pallet system and selection of power pack based on the given load requirements by the manufacturer.

\section{LIFTING MECHANISM}

\subsection{Pallet Design}

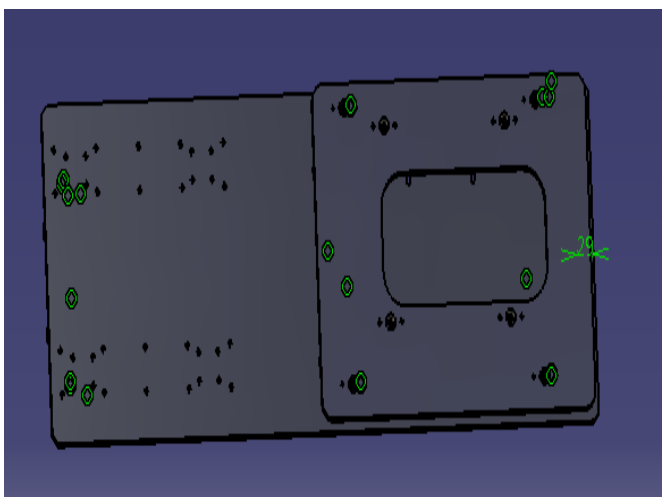

Fig.2: Pallet Design

It consists of two parallel plate mounted on top of each other via hydraulic actuators. The smaller one is mounted on the top and is responsible for vertical movement, so as to lift the load .And the bigger one is mounted on the railings of the conveyor via bridge for horizontal movement. An actuator is attached below the bigger plate for horizontal actuation.

The dimensions of the pallet have been selected in such a way as to support the trolley (load), which is a standard one provided, by the manufacturer.

\subsection{Problem Statement}

There were various problems encountered while lifting the load with the help of actuators. Some of the major are listed below:

- Unbalancing caused due to failure of either actuator

- Non uniform transmission of force

- Jerk, due to sudden back pressure created while lowering

- Vibrations

\subsection{Proposed Work}

In order to eliminate the above listed problems, an additional mechanism was introduced to support the actuation .Main feature of our design is listed below:

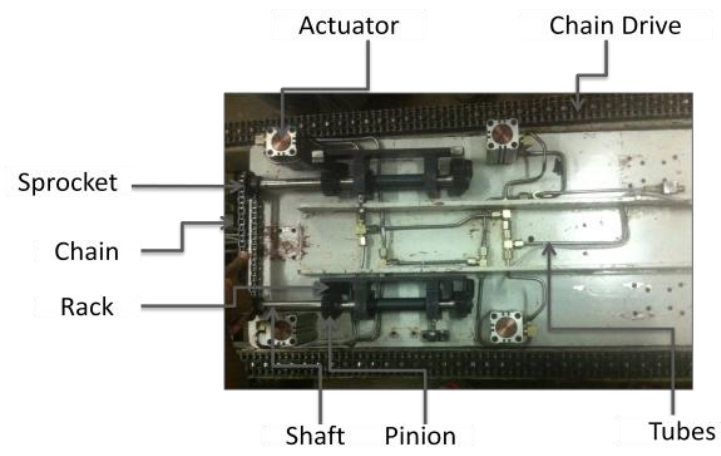

Fig.3:

- Our proposed mechanism is illustrated in the above figure. In additional to the vertical movement of the actuator, rack and pinion system were introduced

- The rack is provided along with the actuator and supports the load bearing plate.

- The pinion transmits motion to the shaft mounted on the lower plate via bearings.

- There are two such shafts, each transmitting set of motion from the four analogous rack and pinion.

- These shafts are interconnected to each other by means of chain and sprocket, so as to transmit motion equally.

- So even if one of the actuator fails ,the motion of the other three is transmitted over the plate through the chain sprocket mechanism

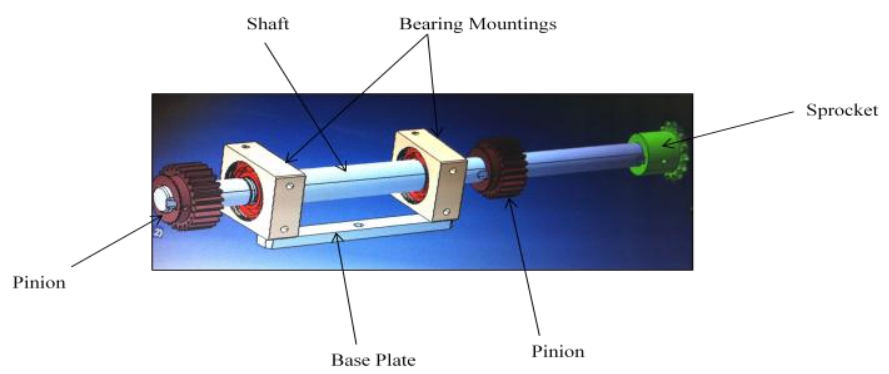

Fig.4

\section{ANALYSIS}

Our proposed mechanism has been designed using CAD software CATIA and is been further analyzed under variable loading in ANSYS.

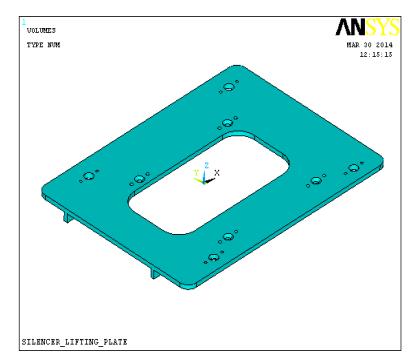

a)

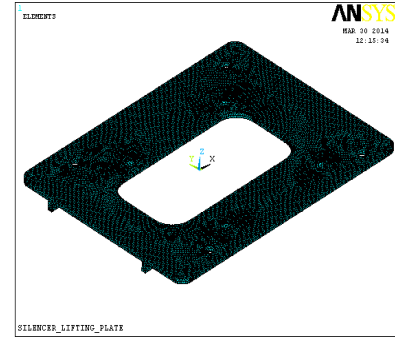

b) 


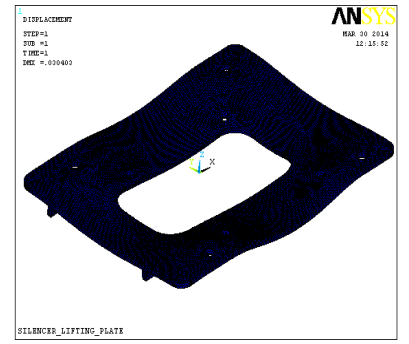

c)

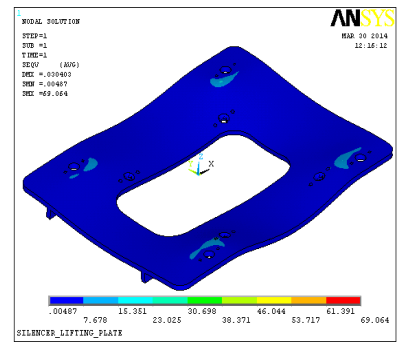

d)

The above figures depict the analysis of the pallet under a load of $250 \mathrm{Kg}$ using ANSYS. Figure $\mathrm{a}$ and $\mathrm{b}$ shows the volume distribution in solid and meshed form. When given a uniform load of $250 \mathrm{Kg}$ the plate made of cast iron shows the above deflection. As seen in the Von misses stress diagram in fig d, the stress concentration is maximum on the four corners of the actuator mountings. As the observed stress concentration is less than the one we assumed considering its factor of safety, Its considers as a safe design able to sustain a given load for a specific amount of time. Analysis is carried for multiple load ranging from $250-500 \mathrm{~kg}$ and its stress diagram is studies. The maximum sustainable load is found out to be around $1000 \mathrm{~kg}$, considering various safety factors.

\section{REFRENCES}

[1] J.J. Uicker, G.R. Pennock, J.E. Shigley, Theory of Machines and Mechanisms, Oxford University Press, New Delhi 110001, (2009)319-354

[2] WANG Ying and ZHOU Chen "A Model and an analytical method for conveyor system in distribution centers", J Syst Sci Syst Eng., 19(4): 408-429 (Dec. 2010).

[3] Long R., Rom T., Ansel W.H., Ansch T.W.H. and Reichel J. "Long distance magnetic conveyor for precise positioning of ultra cold atoms" Eur. Phys. J.D. 35, 125-133 (2005)

[4] LI Baoren, ZHANG Qingxian, DU Jingmin. Investigations on vacuum servo control system based on fuzzy control[J]. Journal of Huazhong University of Science and Technology, 1999, 27(11): 65-67.

[5] Kamble, N. and Saha, S.K. (2005a) 'Effect of pinion profile modification on Rack and Pinion Steering gear, 2005-01-1273', Proc. Steering-Suspensions, Tire and Wheels, SP 1915, pp.83-90. 